\title{
Relative safety profiles of high dose statin regimens
}

\author{
Carlos Escobar \\ Rocio Echarri \\ Vivencio Barrios \\ Department of Cardiology, Hospital \\ Ramón y Cajal, Madrid, Spain
}

Correspondence:Vivencio Barrios Department of Cardiology, Hospital Ramón y Cajal, Ctra. De Colmenar km 9.10028034 , Madrid, Spain

Tel +34913368259

Fax $+349 / 3368665$

Email vbarriosa@meditex.es/

vbarrios.hrc@salud.madrid.org

\begin{abstract}
Recent clinical trials recommend achieving a low-density lipoprotein cholesterol level of $<100 \mathrm{mg} / \mathrm{dl}$ in high-risk and $<70 \mathrm{mg} / \mathrm{dl}$ in very high risk patients. To attain these goals, however, many patients will need statins at high doses. The most frequent side effects related to the use of statins, myopathy, rhabdomyolysis, and increased levels of transaminases, are unusual. Although low and moderate doses show a favourable profile, there is concern about the tolerability of higher doses. During recent years, numerous trials to analyze the efficacy and tolerability of high doses of statins have been published. This paper updates the published data on the safety of statins at high doses.
\end{abstract}

Keywords: statins, high doses, tolerability, liver, muscle

\section{LDL-cholesterol and cardiovascular disease}

Coronary heart disease (CHD) is the most frequent cause of morbidity and mortality not only in Western countries but also in newly industrialized nations. Data from the National Health and Nutrition Surveys (NHANES) suggest that more than 13 million people in the United States have CHD and that, significantly, prevalence increases with age. Prevalence increases from $7 \%$ at ages 40 to 49 years to $22 \%$ at 70 to 79 years in men, and from 5\% to $15 \%$ in women (Ergin et al 2004). Mortality rates for cardiovascular disease and CHD in men and women have decreased in most developed countries by $25 \%$ since 1975 , although the decline has slowed since 1990 (Kuulasmaa et al 2000; Menotti et al 2004). This reduction is a consequence mainly of better treatments, including improved cholesterol control. In contrast, mortality from CHD is estimated to be increasing in developing countries (including Latin America, the Middle East, China, India, and sub-Saharan Africa), probably due to social and economic changes in non-Western countries, physical inactivity, an increase in cigarette smoking, or Westernized diets (Okrainec et al 2004).

Data from epidemiological studies clearly indicates that elevated low-density lipoprotein (LDL) cholesterol (LDL-C) is a major cause of CHD. Furthermore, recent clinical trials strongly demonstrate that LDL-lowering therapy reduces the risk of CHD (NCEP-ATP III 2001; ALLHAT 2002; Heart Protection Study Collaborative Group 2002; Shepherd et al 2002; Sever et al 2003; Barrios et al 2005). The 2001 ATP III report proposed that for secondary prevention, dietary and lifestyle modifications should be adopted by any patient with an LDL-C exceeding $100 \mathrm{mg} / \mathrm{dL}$, and drug therapy given if the LDL-C remains above $130 \mathrm{mg} / \mathrm{dL}$. According to these recommendations drug therapy was considered optional in patients with LDL-C values between 100 and $129 \mathrm{mg} / \mathrm{dL}$ (NCEP-ATP III 2001). However, new studies published after the ATP III report led the NCEP to propose modifying previous guidelines. The Panel suggested starting drug therapy for patients with an LDL-C above $100 \mathrm{mg} / \mathrm{dL}$ and CHD or CHD equivalents, and considering an additional goal of LDL below $70 \mathrm{mg} / \mathrm{dL}$, especially in very high-risk patients (Grundy et al 2004) (Table 1). 
Table I NCEP-ATP III LDL cholesterol objectives and cutpoints drug therapy according to risk categories (Adapted from Grundy et al 2004)

\begin{tabular}{|c|c|c|}
\hline Risk category & LDL-C objective & $\begin{array}{l}\text { LDL-C level at which to consider drug } \\
\text { therapy }\end{array}$ \\
\hline $\begin{array}{l}\text { High risk: } \text { CHD or CHD risk equivalent } \\
(\text { I } 0 \text {-year risk }>20 \%)\end{array}$ & $\begin{array}{l}<100 \mathrm{mg} / \mathrm{dL}(2.58 \mathrm{mmol} / \mathrm{L}) ; \text { optional goal }<70 \\
\mathrm{mg} / \mathrm{dL}(1.82 \mathrm{mmol} / \mathrm{L}) \text { in very high risk patients }\end{array}$ & $\begin{array}{l}\geq 100 \mathrm{mg} / \mathrm{dL}(2.58 \mathrm{mmol} / \mathrm{L}) ;<100 \mathrm{mg} / \mathrm{dL} \\
(2.58 \mathrm{mmol} / \mathrm{L}) \text { consider drug options }\end{array}$ \\
\hline $\begin{array}{l}\text { Moderately high risk: } 2 \text { or more risk factors } \\
\text { (10-year risk } 10 \text { to } 20 \% \text { ) }\end{array}$ & $<130 \mathrm{mg} / \mathrm{dL}(3.36 \mathrm{mmol} / \mathrm{L})$ & $\begin{array}{l}\geq 130 \mathrm{mg} / \mathrm{dL}(3.36 \mathrm{mmol} / \mathrm{L}) ; 100 \text { to } 129 \mathrm{mg} / \mathrm{dL} \\
\text { consider drug options }\end{array}$ \\
\hline $\begin{array}{l}\text { Moderate risk: } 2 \text { or more risk factors } \\
(10 \text {-year risk }<10 \%)\end{array}$ & $<130 \mathrm{mg} / \mathrm{dL}(3.36 \mathrm{mmol} / \mathrm{L})$ & $\geq 160 \mathrm{mg} / \mathrm{dL}(4.13 \mathrm{mmol} / \mathrm{L})$ \\
\hline Lower risk: 0 to I risk factor & $<160 \mathrm{mg} / \mathrm{dL}(4.13 \mathrm{mmol} / \mathrm{L})$ & $\begin{array}{l}\geq 190 \mathrm{mg} / \mathrm{dL}(4.91 \mathrm{mmol} / \mathrm{L}) ; 160 \text { to } 189 \mathrm{mg} / \mathrm{dL} \\
\text { consider drug options }\end{array}$ \\
\hline
\end{tabular}

Notes: CHD risk equivalents include noncoronary forms of atherosclerotic disease (peripheral arterial disease, abdominal aortic aneurysm, and carotid artery disease), and diabetes mellitus. Risk factors include age, hypertension, family history of premature CHD cigarette smoking, low HDL cholesterol.

Abbreviations: CHD, coronary heart disease; LDL-C, low density lipoprotein-cholesterol.

\section{Why high doses of statins?}

Some trials that aimed to sustain a more aggressive lipidlowering therapy showed consistent benefits, but others have shown paradoxical results (Cannon et al 2004; de Lemos et al 2004; Nissen et al 2004; LaRosa et al 2005; Pedersen et al 2005). To clarify whether intensive lipid lowering with statin therapy improved cardiovascular outcomes, a meta-analysis of the four large studies (TNT, IDEAL, A-to-Z Phase Z, and PROVE IT-TIMI-22) compared intensive with moderate lipid-lowering strategies (Cannon et al 2006). These trials enrolled more than 27,000 patients; intensive-therapy subjects had a mean LDL-C of $75 \mathrm{mg} / \mathrm{dL}$, in contrast to $101 \mathrm{mg} / \mathrm{dL}$ for moderate therapy. Patients who received intensive therapy showed a significant, $16 \%$ risk reduction in coronary death or myocardial infarction ( $\mathrm{p}<0.00001)$, a reduction of $16 \%$ in coronary death or any cardiovascular event $(\mathrm{p}<0.00001)$, and an $18 \%$ reduction in the risk of stroke versus moderate statin therapy $(p=0.012)$. No difference was observed in total or non-cardiovascular mortality, but a trend toward decreased cardiovascular mortality in the limit of significance (risk reduction $12 \%, \mathrm{p}=0.054$ ) was found. Authors concluded that intensive lipid lowering therapy with statins provided a significant benefit over standard-dose statin treatment for preventing non-fatal cardiovascular events, including stroke and, furthermore, tended to decrease cardiovascular mortality, which favors a broader use of intensive statin therapy for patients with stable coronary heart disease, as well as those with a recent acute coronary syndrome (Figure 1).

More recently, another meta-analysis analyzed the effects of high-dose statins in patients with acute coronary syndrome, a particularly high-risk group (Hulten et al 2006). A total of 13 randomized, controlled trials, involving 17,963 adults were included in the analysis. This study showed that early, intensive statin therapy for acute coronary syndromes decreased the rate of death and cardiovascular events over 2 years of follow-up (hazard ratio, $0.81, \mathrm{p}<0.001$ ); survival curves revealed that this benefit begins between 4 and 12 months, achieving statistical significance by 12 months. These results are not surprising, given that intensive lipidlowering treatment with statins has been shown to reduce progression of coronary atherosclerosis in patients with coronary heart disease (Nissen et al 2004; Nicholls et al 2007).

Because the prevalence of CHD increases with age, it is important to understand the effects of aggressive statin therapy in the elderly. A post hoc analysis of the MIRACL study (Olsson et al 2007) compared benefits of $80 \mathrm{mg}$ of atorvastatin in older ( $\geq 65$ years) versus younger $(<65$ years) patients. The combined primary end point was nonfatal acute myocardial infarction, resuscitated cardiac arrest, and recurrent symptomatic myocardial ischemia. Event rates were approximately two to three-fold higher in older patients. Interestingly, treatment-by-age heterogeneity testing showed no difference in treatment effect by age for any of the primary or secondary end points. Relative risk reductions in the primary end point with the statin (atorvastatin) versus placebo, were similar in younger and older patients ( $22 \%$ and $14 \%$, respectively). A prespecified secondary analysis of the Treating to New Targets (TNT) study, a randomized, double-blind clinical trial, aimed to assess the efficacy and safety of high-dose atorvastatin in patients $\geq 65$ years (Wenger et al 2007). A total of 10,001 patients (3809 patients $\geq 65$ years of age) with CHD and LDL-C levels $<130 \mathrm{mg} / \mathrm{dL}$ were included. Patients were randomly assigned to receive atorvastatin, 10 or $80 \mathrm{mg} / \mathrm{d}$. In this study, absolute risk was reduced by $2.3 \%$ and relative risk by $19 \%$ for major cardiovascular events, in favor of the high-dose atorvastatin group in patients $\geq 65$ years. Therefore, 


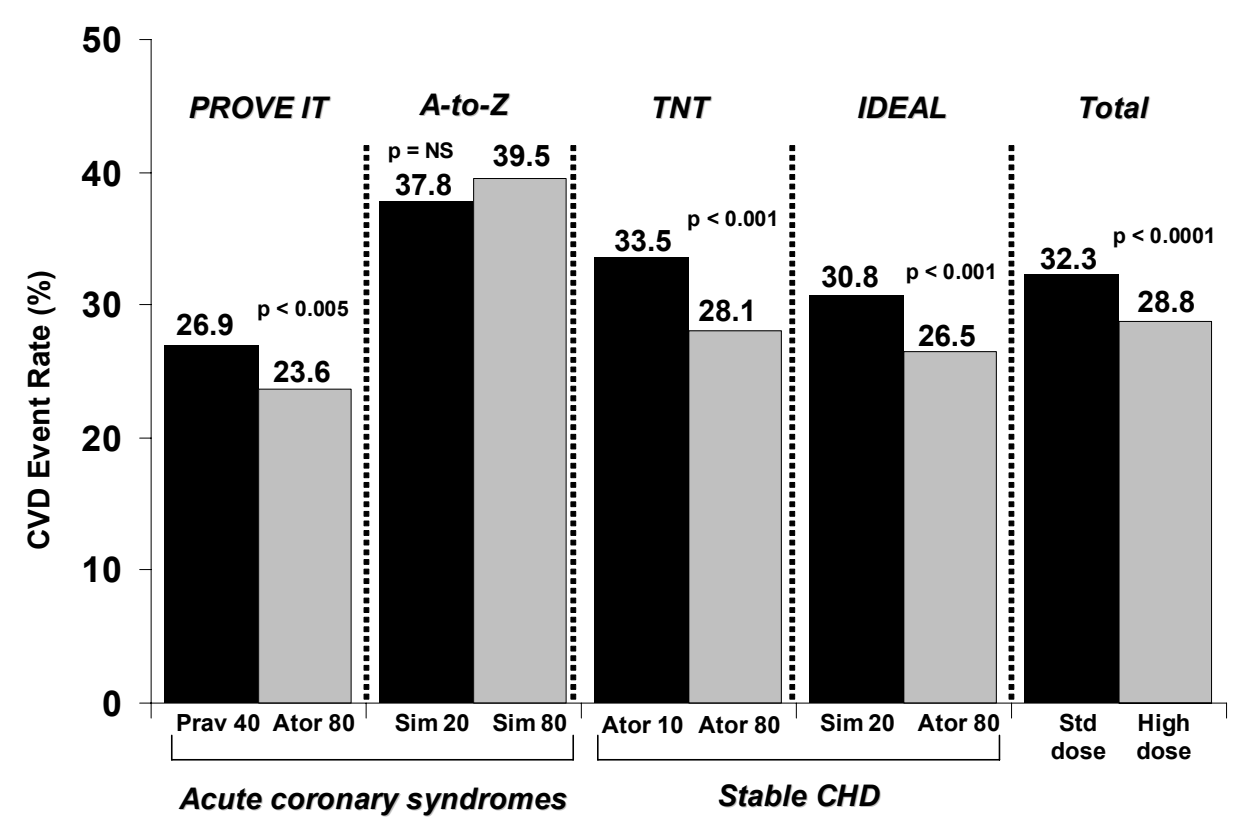

Figure I Risk of coronary risk or any cardiovascular event (myocardial infarction, stroke, hospitalization for unstable angina or revascularization) (Cannon et al 2006). Abbreviations: CVD, cardiovascular diseases; CHD, coronary heart disease; prav, pravastatin; ator, atorvastatin; sim, simvastatin; std, standard.

additional clinical benefit can be achieved by treating older patients with CHD more aggressively, to reduce LDL-C $<100 \mathrm{mg} / \mathrm{dL}$.

However, although recent clinical trials found that highdose, compared with conventional-dose, statin therapy clearly reduces the risk of cardiovascular events in patients with stable CHD and acute coronary syndromes, whether this approach was cost-effective was unclear. For this reason, Chan and colleagues (2007) designed a Markov model to compare daily high-dose with conventional-dose statin therapy for hypothetical 60-year-old cohorts with CHD over patient lifetime. In this study, a high-dose statin strategy was potentially highly effective, and cost-effective, in patients with acute coronary syndrome. Nonetheless, in patients with stable CHD, the cost-effectiveness of high-dose statin treatment was highly sensitive to model assumptions about lipidlowering efficacy and cost. Therefore, the use of high-dose statins may be supported on health economic grounds for patients with acute coronary syndrome, but not necessarily for patients with stable CHD (Chan et al 2007).

\section{Safety of high doses of statins}

All these data show that high-dose statins are effective in reducing cardiovascular outcomes in patients with stable $\mathrm{CHD}$ and/or acute coronary syndrome. However, the clinical utility of statins depends not only on the capacity to reduce LDL-C values, but also on its tolerability profile. If a drug is well tolerated, treatment compliance and efficacy will increase (Jacobson 2006; Davidson and Robinson 2007). The first statin introduced was lovastatin in 1987 (Downs et al 1998). Numerous studies have analyzed the incidence and prevalence of side effects related to statins. Although these studies had shown low rates of adverse events, cerivastatin was withdrawn in 2001 due to the significant risk of muscle toxicity at higher doses (Davidson 2002; Staffa et al 2002; US FDA 2005). Therefore the statins do not all have the same side effects profile, so that the results obtained for one statin in clinical trials can not be translated to others. Furthermore, because randomized clinical trials have a limited number of patients, who do not always accurately represent the "real world" of clinical practice, vigilance in the use of these drugs in daily clinical practice is essential. Because "real world" patients commonly belong to high-risk groups, are polymedicated and have more co-morbidities, the rates of adverse events may be higher in clinical practice than those published in clinical trials (Rosser 1999; Armitage 2007; Barrios et al 2007; Steg et al 2007). The clinical characteristics that increase the probability of presenting side effects are shown in Table 2 (Davidson and Robinson 2007). The most important adverse events related to the use of statins are muscle toxicity and the effects on liver enzymes (Armitage 2007; Davidson and Robinson 2007). Table 3 shows the rates of severe adverse events from large randomized trials of intensive statin therapy. 
Table 2 Clinical characteristics that increase the probability of presenting side effects from randomized clinical trials (modified from Davidson and Robinson 2007)

\begin{tabular}{|c|c|}
\hline Clinical characteristics & Situation that increases risk \\
\hline Age & $\geq 75$ years \\
\hline Heart failure & Left ventricular ejection fraction $<30 \%$ \\
\hline Intercurrent illness, surgery, or trauma & $\begin{array}{l}\text { Concomitant use of statins when major surgery, severe illness, or major trauma } \\
\text { is present }\end{array}$ \\
\hline Comorbidities or concomitant treatments & Multiple comorbidities or therapies \\
\hline Alcohol intake & Excessive alcohol intake ( $>2$ drinks per day) \\
\hline Concomitant lipid-lowering therapy & Fibrates, especially gemfibrozil \\
\hline Cytochrome P450 inhibitors & $\begin{array}{l}\text { Concomitant use of: macrolide antibiotics, antiviral drugs (especially HIV } \\
\text { protease inhibitors), systemic azole antifungals (itraconazole and ketokonazole), } \\
\text { nefazadone, grapefruit juice }>\text { I quart/day }\end{array}$ \\
\hline Immunosuppressive therapy & Especially ciclosporine \\
\hline Muscle function & $\begin{array}{l}\text { CK }>3 \times \text { ULN unless explanationHistory of muscle disease Continuing with } \\
\text { statin therapy after strenuous exercise }\end{array}$ \\
\hline Hepatic function & Active hepatic disease ALT and AST $>2 \times$ ULN \\
\hline Renal function & $\begin{array}{l}\text { Creatinine }>1.5 \times \text { ULN Glomerular filtration rate }<60 \mathrm{ml} / \mathrm{min} / 1.73 \mathrm{~m}^{2} \text { History } \\
\text { of nephrotic syndrome }\end{array}$ \\
\hline
\end{tabular}

Abbreviations: ALT, alanine aminotransferase; AST, aspartate aminotransferase; CK, creatine kinase; ULN, upper limit of normal.

\section{Muscle toxicity}

Before analyzing the effects of statin on the muscle, several specialist must be defined (Christopher-Stine 2006; Harper and Jacobson 2007). The American College of Cardiology, the American Heart Association, and the National Heart, Lung and Blood Institute have defined the terms used when discussing statin-related muscular symptoms and disease (Pasternac et al 2002). Myopathy is a general term for any muscle symptom or pathology. Myalgia refers to symptoms without creatinine kinase (CK) elevation. Myositis can be defined as muscular symptoms with an elevation in CK, and rhabdomyolysis as muscle symptoms with CK elevation greater than 10 times the upper limit of normal, with a serum creatinine elevation and the occasional presence of brown urine with urinary myoglobin (Pasternac et al 2002; Harper and Jacobson 2007).
Although the mechanism of myopathy related to statins is under investigation, several theories have been proposed to explain this side effect. One is a deficiency of coenzyme Q10, which is a product of the 3-hydroxy-3-methylglutarylcoenzyme A reductase pathway (Paiva et al 2005). Because coenzyme Q10 plays a key role in the electron transport chain, a decrease in this coenzyme may cause abnormal mitochondrial respiratory function (Harper and Jacobson 2007). Other theories have associated reduced cholesterol levels, which could alter the myocyte membrane cholesterol, and depletion of isoprenoids, which are synthesized through the 3-hydroxy-3-methylglutaryl-coenzyme A reductase pathway and control myofiber apoptosis, with statin-induced myopathy (Westwood et al 2005; Dirks and Jones 2006). On the other hand, a distinct difference in the pharmacokinetics of atorvastatin metabolites, between

Table 3 Severe adverse events from large randomized trials of intensive statin therapy (data from Cannon et al 2004; de Lemos et al 2004; LaRosa et al 2005; Pedersen et al 2005)

\begin{tabular}{|c|c|c|c|c|}
\hline & PROVE-IT $(n=4,162)$ & A-to-Z $(n=4,497)$ & TNT $(n=10,001)$ & IDEAL $(n=\mathbf{8}, \mathbf{8 8 8})$ \\
\hline $\begin{array}{l}\text { AST and/or ALT }>3 \times \text { ULN } \\
\text { Higher vs lower }\end{array}$ & $3.3 \%$ vs $1.1 \%, p<0.00 I$ & $0.9 \%$ vs $0.4 \%, p=0.05$ & I. $2 \%$ vs $0.2 \%, p<0.00$ I & $0.97 \%$ vs $0.11 \%, p<0.001$ \\
\hline $\begin{array}{l}\mathrm{CK}>10 \times \text { ULN Higher vs } \\
\text { lower }\end{array}$ & $0.1 \%$ vs $0.15 \%, p=N S$ & $0.4 \%$ vs $0.04 \%, p=0.02$ & $0 \%$ vs $0 \%, p=N S$ & $0.14 \%$ vs $0.25 \%, p=N S$ \\
\hline $\begin{array}{l}\text { Rhabdomyolysis Higher vs } \\
\text { lower }\end{array}$ & $0 \%$ vs $0 \%, p=N S$ & $0.1 \%$ vs $0 \%$ & $0.04 \%$ vs $0.06 \%, p=N S$ & $0.05 \%$ vs $0.07 \%, p=N S$ \\
\hline
\end{tabular}

Abbreviations: ALT, alanine aminotransferase; AST, aspartate aminotransferase; CK, creatine kinase; ULN, upper limit of normal. 
patients with atorvastatin-related myopathy and healthy control subjects, has been reported (Hermann 2006). These hypotheses all have limitations, however, and probably all may play a role (Harper and Jacobson 2007).

All statins may occasionally cause myopathy, which can progress to rhabdomyolysis. Myopathy has been estimated to occur in less than one in 10,000 patients at standard doses of statins. The risk does increase with higher statin doses, although it remains very low (Armitage 2007). In other words, no excess risk of myopathy has been reported with atorvastatin $80 \mathrm{mg}$ daily, compared with standard doses in most randomized clinical trials. However, the A-to- $Z$ trial compared the use of simvastatin $80 \mathrm{mg}$ with simvastatin 20 mg in 4,497 patients suffering from acute coronary syndrome. Higher doses showed a slightly higher risk of myopathy (de Lemos et al 2004). The higher incidence of myopathy and rhabdomyolysis with simvastatin may result in part from a reduced rate of plasma clearance in older patients, while clearance is not modified by age for atorvastatin or rosuvastatin, what could partly explain these different toxicity rates (Simvastatin PI 2005; Rosuvastatin PI 2006; Atorvastatin PI 2006; Davidson and Robinson 2007). A higher risk of myopathy has been shown with doses above $20 \mathrm{mg}$ of rosuvastatin, though no morbidity and mortality trials have yet been completed for this drug, to establish long-term safety comparisons with other statins at high doses (Rosuvastatin PI 2006; Armitage 2007; Davidson and Robinson 2007).

Although the risk of myopathy is low, when starting with drugs that interact with statins, especially gemfibrozil, the probability of presenting side effects increases within a few months of starting statin treatment or of increasing the dose, even after some years of apparently stable statin treatment (Armitage 2007). The drugs that most commonly increase the toxicity of statins are cyclosporine and those affecting metabolism via cytochrome P450 or glucuronidation (Ballantyne et al 2003; Bays 2006). Therefore, the drugs that are metabolized by these systems may modify levels of statins, and their toxicity (Davidson and Robinson 2007). Importantly, gemfibrozil inhibits glucuronidation, thereby increasing statin serum levels, but fenofibrate is a weaker inhibitor. Approximately $40 \%$ of all statin rhabdomyolysis cases have been reported to occur with statin + fibrate combinations, but mainly when gemfibrozil is associated with statins (Davidson and Robinson 2007).

The most appropriate approach for screening and management of myopathy is not yet clear. As an example, the American Heart Association and the National Heart, Lung and Blood Institute Statin Advisory Panel, have recommended the measurement of $\mathrm{CK}$ before starting treatment with stains, while the National Lipid Association Muscle Expert Panel does not consider it necessary (McKenney et al 2006; Harper and Jacobson 2007). However, as Harper et al suggest, it seems reasonable to measure baseline CK values in high-risk patients, such as those included in Table 2. Obviously, it is mandatory to determine CK values in those patients under statin therapy, who have muscle-related symptoms. When CK increases, other causes need to be ruled out, such as infections, seizures, hypothyroidism, trauma or strenuous physical activity. Moreover, clinicians should be careful with the use of concomitant drugs or situations that can interact with statins (Harper and Jacobson 2007). As the National Lipid Association Statin Safety Assessment Task Force recommend, if a patient presents intolerable muscle symptoms, statin should be withdrawn regardless of CK levels and reconsidered only after the subject becomes asymptomatic. If symptoms are tolerable, the approach will differ according to $\mathrm{CK}$ levels. Thus if $\mathrm{CK}$ values are mildly increased ( $<10$ times the upper limit of normal), statins may be continued. If the patient develops muscle symptoms, statin should be discontinued. If CK levels are moderate to severely elevated, the statin treatment regime may be paused, while risks and benefits are considered. Finally, if the rise in CK levels is associated with elevated creatinine or need for intravenous hydration, statins should be discontinued (Pasternac et al 2002; Harper and Jacobson 2007). Although small clinical trials and case reports have been published concerning coenzyme Q10 as prophylaxis or treatment for statin myopathy, this approach is still not recommended until large randomized clinical trials have been completed (Horvath et al 2006; Harper and Jacobson 2007). However, we should not forget that although rhabdomyolysis is potentially lethal, its incidence is really very low, and the benefits of statins are unquestionable.

\section{Liver enzymes and statins}

Asymptomatic increases of liver enzymes, as much as $>3$ times the upper limit of normal, have been reported in patients treated with statins (Cohen et al 2006). Some theories have been proposed to explain these elevations, but their cause has not yet been determined. However, it is clear that patients treated with statins show a higher incidence of liver transaminases levels when compared with placebo (Bays 2006). Data from clinical trials have shown that incidence of transaminases $>3$ times the upper limit of normal is $<1 \%$ in patients treated with intermediate doses, and about 2\%-3\% at higher doses (McKenney et al 2006). Therefore 
a small percentage of patients taking statins experience an increase in liver enzymes, usually during the first six months of treatment. This side-effect is commonly asymptomatic and reversible after discontinuing statin, dose reduction, or even changing to other statins which are less likely to increase liver enzymes (Dale 2007). The effect on transaminases seems to be dose dependent, in the same way as the effects on other liver enzymes and bilirubin, which appear with higher doses. But even at high doses, these liver-enzyme increases have not been clearly associated with hepatitis or liver failure. Importantly, there is no convincing evidence from the statin trials that increases in either transaminases are associated with liver damage (Armitage 2007).

The National Lipid Association Muscle Expert Panel recommend that baseline liver transaminase levels should be obtained during routine general evaluation of patients being considered for treatment with statins, and that if these are abnormal, the cause should be established using supplementary tests. Although routine monitoring of liver enzymes is not supported by the available evidence, it is advisable to repeat the determination 12 weeks after initiating therapy, after a dose increase, and periodically thereafter, and obligatorily when symptoms and signs potentially related to hepatotoxicity appear. If there is an objective evidence of significant liver injury in a patient receiving a statin, the statin should be discontinued. Finally, if an isolated asymptomatic transaminase level is found to be elevated 1-3 times the upper limit of normal, statins can be continued. If it is $>3$ times, the test should be repeated and, if still elevated, and other causes have been ruled out, the decision should be taken on a case by case basis, including discontinuing the drug, reducing the dose, or even persisting with treatment, while weighing the risks and benefits (McKenney et al 2006). However, in a recent publication, Armitage suggested that routine monitoring of liver function after starting statin treatment is no longer recommended for simvastatin, pravastatin, or lovastatin up to $40 \mathrm{mg}$ daily, but is still recommended for the other statins, and for higher doses. As in previous recommendations, if an asymptomatic patient treated with statins shows transaminases $>3$ times the upper limit of normal, with no other liver abnormalities, the enzymes should be checked within a week, but if the alteration persists, statin treatment should be stopped temporarily (Armitage 2007).

Clinical trials have shown that high-dose statins are reasonably well tolerated, but discontinuation rates as a result of unspecified drug-related side effects, while relatively low, remain high when high doses are used (Davidson and Robinson 2007). A recently published paper, which included 23 statin treatment arms with 309,506 personyears of follow-up, showed that the risk of statin-associated elevated liver enzymes or rhabdomyolysis do not seem to be related to the magnitude of LDL-C lowering. In other words, drug-specific and dose-specific effects are more important determinants of liver and muscle toxicity than the extent of LDL-C lowering (Alsheikh-Ali et al 2007).

\section{Other adverse events and high-dose statins}

Although cases of renal failure have been reported in patients receiving statin therapy, such events are uncommon and similar to placebo. In fact in the absence of rhabdomyolysis, renal failure does not appear to be related to treatment with statins (Davidson et al 2006; Kasiske et al 2006; McKenney et al 2006). Moreover, data from small randomized clinical trials, and post hoc analyses of large trials, suggest that statins may even slow the rate of decline in renal function (Kasiske et al 2006; McKenney et al 2006). Nevertheless, researchers have reported that rosuvastatin could be associated with a rise in the risk of proteinuria, especially at higher doses (Davidson et al 2006; Kasiske et al 2006; Armitage 2007). Statin treatment has also been linked with sleep disturbance, dementia, peripheral neuropathy, lens opacities, or mood disorders, results from large clinical trials have not confirmed any of these adverse events (Gerson et al 1990; Morgan et al 1993; Wardle et al 1996; Gaist et al 2001; Wagstaff et al 2003; Heart Protection Study Collaborative Group 2004; Brass et al 2006; Armitage 2007).

One important concern about treatment with statins is the potential link with cancer. However, a prospective metaanalysis, which included 90,056 patients from 14 randomized clinical trials who were treated with moderate doses of statins during a 6-year follow-up, showed equivalent rates of cancer when compared with placebo (Cholesterol Treatment Trialists' Collaborators 2005). Similarly, in the TNT trial that compared atorvastatine $80 \mathrm{mg}$ versus $20 \mathrm{mg}$, and in the IDEAL study that compared atorvastatine $80 \mathrm{mg}$ with simvastatin $20 \mathrm{mg}$, the incidence of cancer did not differ between groups (LaRosa et al 2005; Pedersen et al 2005; Davidson and Robinson 2007). However, the controversy has very recently revived. The latest published meta-analysis included as a secondary endpoint the risk of cancer in 23 statin treatment arms with 309,506 person-years of follow-up. It showed a significant inverse association between cancer incidence and achieved LDL-C levels, whereas no such association was demonstrated with percent LDL-C reduction or absolute LDL-C reduction (Alsheikh-Ali et al 2007). Although the 
authors themselves recognize that this study was exploratory and hypothesis-generating, and that these findings did not demonstrate causality between low achieved LDL-C levels or statin use and cancer, these results have reopened the debate about the risk of cancer and statins.

Because low cholesterol levels are associated with a poor prognosis in patients with heart failure, there is also concern about the possibility that statins could be harmful in these patients (Horwich et al 2002; Krum and McMurray 2002; Ashton et al 2003; Rauchhaus et al 2003). However, the contrary data provided from subgroup and retrospective analyses, and evidence from prospective cohort studies and small clinical trials, suggest that statins may improve cardiovascular prognosis in heart failure (Raina et al 2006; Scirica et al 2006; Armitage 2007; Khush et al 2007). Recently, the results of the CORONA study have been reported (Kjekshus 2007). In this study, a total of 5011 patients at least 60 years of age with New York Heart Association class II-IV ischemic, systolic heart failure were randomly assigned to receive $10 \mathrm{mg}$ of rosuvastatin or placebo per day. Rosuvastatin was very well tolerated, with no significant increase of hepatic, renal, or muscular adverse events versus placebo. Significantly, the rate of discontinuations was even higher in the placebo group than in the statin treatment arm. The results of this study together with the data of the two ongoing clinical trials (GISSI-HF and UNIVERSE) will probably conclude the debate about the efficacy and safety of statins even in vulnerable patients such as those with heart failure (Celik et al 2007).

Another important question is the security of statins in the elderly. Recently, two analyses from the TNT and MIRACL trials have shown that the incidence of adverse events is low in patients $\geq 65$ years (Olsson et al 2007; Wenger et al 2007). Thus, no dose adjustment is recommended for elderly patients (Armitage 2007). However, because only a small proportion of patients $>80$ years have been included in clinical trials, caution is needed in the treatment of this very elderly population (Cholesterol Treatment Trialists' Collaborators 2005; Armitage 2007).

\section{Conclusions}

In conclusion, high-dose statins are safe and well-tolerated. The most important side effects related to the use of statins, myopathy and rhabdomyolysis, are rare. However, it should be taken into account that these data have been provided from clinical trials. Because patients included in these studies are usually selected in some way, this incidence could probably increase in daily clinical practice. Therefore caution is needed when treating some groups of patients who are especially vulnerable to side effects, such as those with multiple comorbidities, concomitant treatments, or a history of muscle, hepatic, or renal disease.

\section{References}

ALLHAT Officers and Coordinators for the ALLHAT Collaborative Research Group. 2002. The Antihypertensive and Lipid-Lowering Treatment to Prevent Heart Attack Trial. Major outcomes in moderately hypercholesterolemic, hypertensive patients randomized to pravastatin vs usual care: the Antihypertensive and Lipid-Lowering Treatment to Prevent Heart Attack Trial (ALLHAT-LLT). JAMA, 288:2998-3007.

Alsheikh-Ali AA, Maddukuri PV, Han H, et al. 2007. Effect of the magnitude of lipid lowering on risk of elevated liver enzymes, rhabdomyolysis, and cancer: insights from large randomized statin trials. $J$ Am Coll Cardiol, 50:409-18.

Armitage J. 2007. The safety of statins in clinical practice. Lancet, 370(9601):1781-90

Ashton E, Liew D, Krum H. 2003. Should patients with chronic heart faliure be treated with "statins"? Heart Fail Monit, 3:82-86.

Ballantyne CM, Corsini A, Davidson MH, et al. 2003. Risk for myopathy with statin therapy in high-risk patients. Arch Intern Med, 163:553-64.

Bays H. 2006. Statin safety: an overview and assessment of the data-2005. Am J Cardiol, 97:6C-26C.

Barrios V, Amabile N, Paganelli F, et al. 2005. Lipid-altering efficacy of switching from atorvastatin $10 \mathrm{mg} /$ day to ezetimibe/simvastatin in hypercholesterolaemic patients with atherosclerosis or coronary artery disease. Int J Clin Pract, 59:1377-86.

Barrios V, Escobar C, Calderon A, et al. 2007. Cardiovascular risk profile and risk stratification of the hypertensive population attended by general practitioners and specialists in Spain. The CONTROLRISK study. $J$ Hum Hypertens, 21:479-85.

Brass LM, Alberts MJ, Sparks L. 2006. An assessment of statin safety by neurologists. Am J Cardiol, 97(suppl 8A):86C-88C.

Cannon CP, Braunwald E, McCabe CH, et al. 2004. Intensive versus moderate lipid lowering with statins after acute coronary syndromes. N Engl J Med, 350:1495-504.

Cannon CP, Steinberg BA, Murphy SA, et al. 2006. Meta-analysis of cardiovascular outcomes trials comparing intensive versus moderate statin therapy. J Am Coll Cardiol, 48:438-45.

Celik T, Iyisoy A, Yuksel UC, et al. 2007. The panacea for cardiovascular diseases: The role of statins in the management of heart failure. Int $J$ Cardiol, Aug 8; [Epub ahead of print].

Chan PS, Nallamothu BK, Gurm HS, et al. 2007. Incremental benefit and cost-effectiveness of high-dose statin therapy in high-risk patients with coronary artery disease. Circulation, 115:2398-409.

Cholesterol Treatment Trialists' (CTT) Collaborators. 2005. Efficacy and safety of cholesterol-lowering treatment: prospective meta-analysis of data from 90,056 participants in 14 randomised trials of statins. Lancet, 366:1267-78.

Christopher-Stine L. 2006. Statin myopathy: an update. Curr Opin Rheumatol, 18:647-53.

Cohen DE, Anania FA, Chalasani N. 2006. An assessment of statin safety by hepatologists. Am J Cardiol, 97(suppl 8A):77C-81C.

Crestor (rosuvastatin calcium) [prescribing information]. August 2005. Accessed April 2006. URL: http://www.astrazeneca-us.com/pi/crestor.pdf

Davidson MH. 2002. Controversy surrounding the safety of cerivastatin. Expert Opin Drug Saf, 1:207-12.

Dale KM, White CM, Henyan NN, et al. 2007. Impact of statin dosing intensity on transaminase and creatine kinase. Am J Med, 120:706-12.

Davidson MH, Clark JA, Glass LM, et al. 2006. Statin safety: an appraisal from the Adverse Event Reporting System (AERS). Am J Cardiol, 97(suppl 8A):32C-43C. 
Davidson MH, Robinson JG. 2007. Safety of aggressive lipid management. $J$ Am Coll Cardiol, 49:1753-62.

de Lemos JA, Blazing MA, Wiviott SD, et al. 2004. Early intensive vs a delayed conservative simvastatin strategy in patients with acute coronary syndromes: phase $\mathrm{Z}$ of the $\mathrm{A}$ to $\mathrm{Z}$ trial. JAMA, 292:1307-16.

Dirks AJ, Jones KM. 2006. Statin induced apoptosis and skeletal myopathy. Am J Physiol Cell Physiol, 291:1208-12.

Downs JR, Clearfield DO, Weis S, et al. 1998. Primary prevention of acute coronary events with lovastatin in men and women with average cholesterol levels. JAMA, 279:1615-22.

Ergin A, Muntner P, Sherwin R, et al. 2004. Secular trends in cardiovascular disease mortality, incidence, and case fatality rates in adults in the United States. Am J Med, 117:219-27.

Expert Panel on Detection, Evaluation, and Treatment of High Blood Cholesterol in Adults. 2001. Executive Summary of The Third Report of The National Cholesterol Education Program (NCEP) Expert Panel on Detection, Evaluation, And Treatment of High Blood Cholesterol In Adults (Adult Treatment Panel III). JAMA, 285:2486-97.

Gaist D, Garcia Rodriguez LA, Huerta C, et al. 2001. Are users of lipidlowering drugs at increased risk of peripheral neuropathy? Eur J Clin Pharmacol, 2001; 56: 931-33.

Gerson RJ, MacDonald JS, Alberts AW, et al. 1990. On the etiology of subcapsular lenticular opacities produced in dogs receiving HMG-CoA reductase inhibitors. Exp Eye Res, 50: 65-78.

Grundy SM, Cleeman JI, Merz CN, et al. 2004. Implications of recent clinical trials for the National Cholesterol Education Program Adult Treatment Panel III guidelines. Circulation, 110:227-39.

Harper CR, Jacobson TA. 2007. The broad spectrum of statin myopathy: from myalgia to rhabdomyolysis. Curr Opin Lipidol, 18:401-8.

Heart Protection Study Collaborative Group. 2002. MRC/BHF Heart Protection Study of cholesterol lowering with simvastatin in 20,536 high-risk individuals: a randomised placebo-controlled trial. Lancet, 360:7-22.

Heart Protection Study Collaborative Group. 2004. Effects of cholesterollowering with simvastatin on stroke and other major vascular events in 20,536 people with cerebrovascular disease or other high-risk conditions. Lancet, 363:757-67.

Hermann M, Bogsrud MP, Molden E, et al. 2006. Exposure of atorvastatin is unchanged but lactone and acid metabolites are increased severalfold in patients with atorvastatin-induced myopathy. Clin Pharmacol Ther, 79:532-39.

Horvath R, Schneiderat P, Schoser BG, et al. 2006. Coenzyme Q10 deficiency and isolated myopathy. Neurology, 66:253-5.

Horwich TB, Hamilton MA, Maclellan WR, et al. 2002. Low serum total cholesterol is associated with marked increase in mortality in advanced heart faliure. J Card Fail, 8:216-24.

Hulten E, Jackson JL, Douglas K, et al. 2006. The effect of early, intensive statin therapy on acute coronary syndrome: a meta-analysis of randomized controlled trials. Arch Intern Med, 166:1814-21.

Jacobson TA. 2006. Statin safety: lessons from new drug applications for marketed statins. Am J Cardio, 97(suppl):44C-51C.

Kasiske BL, Wanner C, O’Neill WC. 2006. An assessment of statin safety by nephrologists. Am J Cardiol, 97(suppl 8A):82C-85C.

Khush KK, Waters DD, Bittner V, et al. 2007. Effect of high-dose atorvastatin on hospitalizations for heart failure: subgroup analysis of the Treating to New Targets (TNT) study. Circulation, 115:576-83.

Kjekshus J, Apetrei E, Barrios V, et al. 2007. Rosuvastatin in older patients with systolic heart failure. $N$ Engl J Med, 357:2248-61.

Krum H, McMurray JJ. 2002. Statins and chronic heart failure: do we need a large-scale outcome trial? J Am Coll Cardiol, 8:216-24.

Kuulasmaa K, Tunstall-Pedoe H, Dobson A, et al. 2000. Estimation of contribution of changes in classic risk factors to trends in coronaryevent rates across the WHO MONICA Project populations. Lancet, $355: 675-87$.

LaRosa JC, Grundy SM, Waters DD, et al. 2005. Intensive lipid lowering with atorvastatin in patients with stable coronary disease. $N$ Engl $J$ Med, 352:1425-35.
Lipitor (atorvastatin calcium) [prescribing information]. September 2005. Accessed April 2006. URL: http://www.pfizer.com/pfizer/download/ uspi_lipitor.pdf

McKenney JM, Davidson MH, Jacobson TA, et al. 2006. Final conclusions and recommendations of the National Lipid Association Statin Safety Assessment Task Force. Am J Cardiol, 97:89C-94C.

Menotti A, Kromhout D, Blackburn H, et al. 2004. Forty-year mortality from cardiovascular diseases and all causes of death in the US Railroad cohort of the Seven Countries Study. Eur J Epidemiol, 19:417-24.

Morgan RE, Palinkas LA, Barrett-Connor EL, et al. 1993. Plasma cholesterol and depressive symptoms in older men. Lancet, 341:75-9.

Nicholls SJ, Tuzcu EM, Sipahi I, et al. 2007. Statins, high-density lipoprotein cholesterol, and regression of coronary atherosclerosis. JAMA, 297:499-508.

Nissen SE, Tuzcu EM, Schoenhagen P, et al. 2004. Effect of intensive compared with moderate lipid-lowering therapy on progression of coronary atherosclerosis: a randomized controlled trial. JAMA, 291:1071-80.

Okrainec K, Banerjee DK, Eisenberg MJ. 2004. Coronary artery disease in the developing world. Am Heart J, 148:7-15.

Olsson AG, Schwartz GG, Szarek M, et al. 2007. Effects of high-dose atorvastatin in patients $>$ or $=65$ years of age with acute coronary syndrome (from the myocardial ischemia reduction with aggressive cholesterol lowering [MIRACL] study). Am J Cardiol, 99:632-35.

Paiva H, Thelen KM, Van CR, et al. 2005. High dose statins and skeletal muscle metabolism in humans: a randomized, controlled trial. Clin Pharm Ther, 78:60-68.

Pasternac RC, Smith SC, Bairey-merz CN, et al. 2002. ACC/AHA/NHLBI clinical advisory on the use and safety of statins. $\mathrm{J} \mathrm{Am} \mathrm{Col} \mathrm{Cardiol}$, 40:567-72.

Pedersen TR, Faergeman O, Kastelein JJ, et al. 2005. High-dose atorvastatin vs usual-dose simvastatin for secondary prevention after myocardial infarction: the IDEAL study: a randomized controlled trial. JAMA, 294:2437-45.

Raina A, Pickering T, Shimbo D. 2006. Statin use in heart failure: a cause for concern? Am Heart J, 152:39-49.

Rauchhaus M, Clark AL, Doehner W, et al. 2003. The relationship between cholesterol and survival in patients with chronic heart faliure. $J \mathrm{Am}$ Coll Cardiol, 42:1993-40.

Rosser WW. 1999. Application of evidence from randomised controlled trials to general practice. Lancet, 353:661-64.

Scirica BM, Morrow DA, Cannon CP, et al. 2006. Intensive statin therapy and the risk of hospitalization for heart failure after an acute coronary syndrome in the PROVE IT-TIMI 22 study. J Am Coll Cardiol, 47:2326-31.

Sever PS, Dahlof B, Poulter NR, et al. 2003. Prevention of coronary and stroke events with atorvastatin in hypertensive patients who have average or lower-than-average cholesterol concentrations, in the Anglo-Scandinavian Cardiac Outcomes Trial-Lipid Lowering Arm (ASCOT-LLA): a multicentre randomised controlled trial. Lancet, 361:1149-58

Shepherd J, Blauw GJ, Murphy MB, et al. 2002. Pravastatin in elderly individuals at risk of vascular disease (PROSPER): a randomised controlled trial. PROspective Study of Pravastatin in the Elderly at Risk. Lancet, 360:1623-30.

Staffa JA, Chang J, Green I. 2002. Cerivastatin and reports of fatal rhabdomyolysis. N Engl J Med, 346:539-40.

Steg PG, Lopez-Sendon J, Lopez de Sa E, et al. 2007. External validity of clinical trials in acute myocardial infarction. Arch Intern Med, 167:68-73

US Food and Drug Administration. Baycol Supplementary NDA (0.8 mg dose). FDA Medical Review. Cited July 19, 2000. [US Food and Drug Administration Web site.] Accessed August 30, 2005. URL: http:// www.fda.gov/cder/foi/nda/2000/20-740S008_Baycol_medr.pdf

Wagstaff LR, Mitton MW, Arvik BM, et al. 2003. Statin-associated memory loss: analysis of 60 case reports and review of the literature. Pharmacotherapy, 23:871-80. 
Wardle J, Armitage J, Collins R, et al. 1996. Randomised placebo controlled trial of effect on mood of lowering cholesterol concentration. Oxford Cholesterol Study Group. BMJ, 313:75-8.

Wenger NK, Lewis SJ, Herrington DM, et al. 2007. Outcomes of using high- or low-dose atorvastatin in patients 65 years of age or older with stable coronary heart disease. Ann Intern Med, 147:1-9.
Westwood FR, Bigley A, Randall K, et al. 2005. Statin induced muscle necrosis in the rat: distribution, development, and fibre selectivity. Toxicol Pathol, 33:246-57.

Zocor (simvastatin) [prescribing information]. August 2005. Accessed December 2005 URL: http://www.merck.com/product/usa/pi_circulars/ z/zocor/zocor_pi.pdf 
